\title{
Action research to motivate EFL university students to learn content and language
}

\author{
Teresa Morell Moll \\ Departamento de Filología Inglesa, Universidad de Alicante
}

Recibido: 30 agosto 2004 / Versión aceptada: 26 octubre 2004

\begin{abstract}
The action research carried out by a lecturer of U.S. History and Culture and fourth year English Studies students is an example of how we can make students participate actively in the content and in the process of evaluation. Each unit of the subject is based on a series of questions, which the students answer by way of web searches (or bibliographic searches). In each session students contribute to the discourse and at the end of each unit groups of four students write up possible exam questions. The degree of students' participation, their exam results and their feedback provides evidence of the benefits of involving students in the content and the evaluation of a subject.
\end{abstract}

Key words: action research, US History \& Culture, interactive lecturing, web searches, evaluation.

RESUMEN: La investigación acción (action research) llevada a cabo por una profesora de Historia y cultura de los EE.UU. y alumnos en el cuarto curso de Filología Inglesa es un ejemplo de cómo podemos hacer que los alumnos participen más de forma activa en el contenido y en el proceso de evaluación. Cada unidad de la asignatura se basa en una serie de preguntas planteadas por la profesora y contestadas por los alumnos por medio de búsquedas bibliográficas y a través del Internet. En cada sesión de clase los alumnos aportan la materia y al final de cada unidad un grupo de cuatro alumnos formula posibles preguntas para el examen final. El grado de participación, los resultados del examen y la retroalimentación indican los beneficios de esta metodología.

Palabras clave: investigación acción, Historia y cultura de los Estados Unidos, conferencias interactivas, búsquedas en la Web, evaluación.

\section{INTRODUCTION}

The action research reported on in this paper is a response to the demand for quality education set forth by the Common European Framework of Higher Education, which takes into account the need to enhance students' intrinsic motivation. The demand for quality education leaves little room for scholarly speeches that do not take into account students' present and future reality. It is time for university researchers to direct a greater effort towards improving or making the teaching-learning process more effective. Our research should not only be directed towards our particular fields of interests, but also into the classroom and to our function not only as informers, but as facilitators of knowledge. In the case of EFL 
(i.e. English as a Foreign Language) content lecturers, our task is not only to facilitate our students' learning of the content (e.g. History, Literature, Linguistics, Culture etc.), but also the learning of the English language. Until recently university class time has been dedicated to the traditional lecture, where the instructor simply transmits information in a structured manner and the students listen and take notes. If we truly wish to facilitate our students' learning process of both the content and the language, we need to find more effective ways of involving the students.

University EFL students taking content subjects in English can be provided with an ideal situation for both content and language learning. Wesche \& Ready (1985: 90) claim that gains in second language proficiency are best achieved in situations where the second language is used as a vehicle for communication about other subjects rather than itself. Such is the case for tertiary level students who are enrolled in content courses held in English here in Spain. In fact, the approach, which is used in many English degrees of Spanish universities could be considered "content-based", that is an approach to teaching ESL (or EFL) that attempts to combine language with disciplinary learning, suggesting that teachers can build students' knowledge of concepts in content areas at the same time students are developing English proficiency (Schleppegrell, Achugar \& Oteíza, 2004: 67).

However, learning will only occur if the students are willing to engage in the communicative process, that is, they need to be involved. Lecturers need to devise ways of attracting the students' interests and providing them with the sources that will enable them to receive comprehensible input and to engage in meaningful interactions.

In recent publications there has been a call for interactive lecturing (Frederick, 1987; Flowerdew, 1994; and Morell, 2004a). In other words, the type of classroom event for a large (more than 20) group of students primarily controlled and led by a lecturer and including subject input from the lecturer but also including varying degrees and types of oral participation by students (Northcott, 2001: 19-20). This kind of university classroom event is claimed to be beneficial for students' comprehension of content and language (Dunkel, 1988, and Morell, 2000).

In addition, it appears that allowing for reciprocal discourse within the lecture permits instructors to have a better grasp on the students' level of comprehension, experiential or encyclopedic knowledge, willingness to learn and attention. Questioning our students and encouraging their contributions to the discourse allows us to focus our lessons towards the needs and interests of our students. It also makes us aware of the level of intrinsic and/or extrinsic motivation, that is if they are truly willing to learn or if they are solely moved by their wish to pass the subject (Gardner \& Lambert, 1972). As many lecturers have experienced (Morell \& Aleson, 2004), our students demonstrate more extrinsic motivation, which is made explicit through their greater interest in passing rather than in learning. Consequently, there appears to be a need to enhance their intrinsic motivation. According to González Torres (1997: 34) this implies four basic needs associated with academic motivation: the need for competence, the need for autonomy, the need for an affective connection or relatedness, and the need to find significance in our experiences.

In this paper we will attempt to demonstrate how these needs which are related to intrinsic motivation can be satisfied through a more direct involvement of the students in the content and the evaluation of a course. It describes an action research plan carried out by a lecturer of U.S. History \& Culture and two groups of fourth year students of an English 
Studies degree in a Spanish university. Before describing the participants and the actual study carried out, we will first examine the factors that prompted this study and a review of what is meant by action research.

\section{ThE STUDY}

In view of the European Common Framework for Higher Education and the European Transfer Credit System, the Instituto de las Ciencias de la Educación of the University of Alicante, Spain has coordinated university wide network projects to improve and guarantee quality education. Among the many networks established, one in particular named Exam aimed firstly, to become more familiar with university students' experience and beliefs with regard to the content and the evaluation of subject material and secondly, to determine the effect of integrating the students' into compiling the content of the subject and into the process of evaluation (Morell, T. \& Aleson, $M^{\mathrm{a}}$ A., 2004). The network consisted of 6 lecturers from two faculties (Science and Humanities) and at least eight of the lecturers' groups of students (a total of about 300 students) from five different undergraduate subjects. The lecturer of US History and Culture and two of her groups took part in this project. The study included an initial questionnaire, class discussions, tutorials, tests designed by both lecturers and students, and a final survey. Among the initial results from the first questionnaire, it was found that, in general, students were more extrinsically than intrinsically motivated. In other words, the students were more concerned with obtaining a passing grade than actually learning. As an example of the tools used and of one of the pieces of evidence that led us to this conclusion we will examine one of the items of the initial questionnaire and the proportion of chosen responses.

One of the questions was, "In your opinion, what is the purpose of exams in university?" and it was followed by the following possible responses:
a) to obtain a grade
b) to check to see what you have learned
c) to check to see what you have not learned,
d) to inform you of your progress

$66 \%$ of the students chose 'to obtain a grade' and only $24 \%$ selected 'to check to see what you have learned'. Thus, for the majority, exams are seen as obstacles to be surpassed in order to obtain a degree. In this survey and in class discussions it was also discovered that many students believe that grades measure their ability to take exams rather than their acquired knowledge. Consequently, if lecturers want their students to see exams as a way of checking what they have learned and not just as an obstacle or as a measure of their test taking ability, something needs to be done.

It was also found that students' results on exams are often influenced negatively by time factors and by not knowing exactly what is considered to be important. The following item from the initial questionnaire aided us in arriving at this assertion. The question asked 'Which is the main problem which affects your exam results? 
a) Time

b) The questions do not reflect the content covered

c) The exercises on the exam are not like those carried out in class

d) The questions do not correspond to those you considered to be important while studying for the exam

$38 \%$ of the students responded with ' $\mathrm{d}$ ' that the questions do not correspond to those they considered to be important when studying, and 37\% chose 'a) Time'. Therefore, it appears that as lecturers we need to be explicit about the importance given to the different aspects of the content and when writing up exams we should also be coherent with the previously expressed priorities. In addition, we need to be realistic with the time allotted to respond to exam questions.

These are only two of the items which led us to believe that university students, in general, are not always confronted with ideal situations for effective learning and evaluation. Being that this network project was carried out with students of two distinct faculties from a range of degree studies, a variety of subjects and in different academic year levels, we can deduce that these responses will be similar for most university students. Furthermore, there appears to be a need to reflect on what actually goes on in university classrooms and to find ways of enhancing students' intrinsic motivation.

Until recently issues such as motivation in the classroom have mostly been dealt with at the primary and secondary level of education. Many teachers have attempted different techniques and methodologies to promote their students' motivation, and researchers have carried out studies on the different factors involved. One type of research that has been carried out by teachers in their classrooms is 'action research', that is teacher-initiated classroom investigation which seeks to increase the teacher's understanding of classroom teaching and learning, and to bring about change in classroom practices (Richards \& Lockhart, 1996: 12). It is precisely this type of research that we believe should also be brought into the university classroom.

Tertiary education, much like primary and secondary, needs to be researched to find more effective techniques, methodologies and approaches to improve the teaching and learning process. As has been determined by the network project mentioned and others also reported on in Martínez (2004) and Pastor \& Sauleda (2004), there is plenty of room for research in the university classroom. One of the most practical research techniques that can be carried out by any practicing teacher (instructor or lecturer) at any level of education is "action research".

Action research, as described in the literature (Wallace, 1991; Crookes, 1993; Richards \& Lockhart, 1996; and Gebrard \& Oprandy, 1999), is about teachers reflecting on their own practice in the classroom and identifying and posing problems. It also involves addressing issues and concerns related to the problem. Once the problems and the related issues are identified teachers can set a goal and create and initiate a plan of action. This action plan is then evaluated to determine the degree to which the plan works. Action research was first devised by social psychologists that wished to apply experimental approaches to social science research. Those who first applied it in the field of education believed that formal research following a scientific method had little impact on educational practice. They argued that teachers who study their own practice are more likely to change than by simply reading about 
what someone else had discovered regarding the consequences of teaching (Gebrard \& Oprandy, 1999:61).

Studying one's own teaching practice, to begin with, involves observation and reflection. Once we become aware of our acts and of our students' reactions to them we can begin to form goals to improve the teaching-learning process, which will more than likely involve some form of change. In order for that change to come about we need to devise a plan that we will carry out and simultaneously observe. Finally, we can reflect on the observations and perhaps set a further goal. In essence, this is the structure of action research plans referred to in most of the literature:

1. Setting a goal

2. Planning an action to reach this goal

3. Acting on this plan

4. Observing the action

5. Reflecting on the observation

6. Setting the next goal

The action research reported on in this article is a detailed description of what was done in the US History and Culture class to fulfill the objectives of the Exam network project, which was to determine the effect of integrating the students' into the content of the subject and into the process of evaluation. The students who took part in this study were enrolled in a fourth year English Studies subject called Historia y cultura de los países de habla inglesa (History and Culture of English-Speaking Countries). This is a required 8-credit subject (troncal) and it has been divided, for reasons of convenience, into two major parts: US History and Culture and UK History and Culture. A different lecturer, who is a native of the country studied, gives each part of the course and English is the language used at all times. In this study we will only examine the experience of the students in the US History and Culture part of the course. The 86 students involved formed two groups (A \& B), which took the course in the second semester of the 2002-2003 academic year. The students were mostly from the local area and spoke Spanish or Catalan as a mother tongue. They had between an upper intermediate and advanced level of English language competence according to the Oxford Placement Test. Their ages ranged from 20 to 27. As was determined by a survey, approximately $70 \%$ of the students wanted to become teachers of the English language and the remaining 30\% wished to use English in a business profession.

The lecturer is a native speaker of English (American variety) and she has given the course for six years. Before starting with this action research project she was concerned with improving the students' intrinsic motivation for both learning the content and the language. She believed that the students needed to actively participate with the material of the subject and in the use of the English language.

\section{An action research plan}

In view of the results obtained from the network project coordinated by the Instituto de las Ciencias de la Educación and the experience of former years, the lecturer of US History $\&$ Culture decided to carry out the following action research. She devised the following plan, 
which revolved around the notion of questions for the elaboration of content and of testing material. In essence, the search for knowledge and the evaluation of it is based on questions, that is, if we want to know something as a lecturer or as a student we formulate a question. In the same way, to examine our progress, or that of others, we also form questions. Keeping this in mind, the content of the course and its evaluation was based on both the students' and the lecturer's inquiries.

In the course program and on the first day of class she informed the students that they would be involved in compiling the content of the subject and in designing the tool for evaluation. Their grade for the course would be obtained by taking into account their participation in web searches and reports to class, as well as on their grade of the final exam, which would come from a corpus of questions written by the students.

\section{Compiling the content of the subject}

Each week students would be provided with two or three questions that they would find the answers for via web searches (or bibliographical searches). They would either look for the responses in the recommended bibliography (Campbell \& Kean, 1997; Falk, 1993; and Mauk \& Oakland, 2002), or put key words into searchers (e.g., Google, Altavista, Yahoo) and then read the relevant web pages. Once they had found the required information, they would take note of the reference or web page and summarize the response. In each of the two classes (Group A \& B) one of the students (class secretary) was asked to record the names of the classmates who had done the research, so that they could receive credit for it. The lecturer began each class with the questions on Power Point slides, which were read by students. Those who had done the research were asked to report to the class what they had found. Thus, the students, instead of the lecturer, were providing the class with the content. Once a few students had intervened and they had come up with relevant and comprehensive responses, the lecturer moved onto the slide, which she had prepared beforehand, that reinforced the information found by the students. At the end of each session, the students who had done the web searches would hand in the sheet of paper on which they had recorded the web pages and their summarized responses to the questions. Thus, the lecturer could add to her own corpus of useful web pages having to do with US History and Culture, and these could be posted onto the Virtual Campus (which is a portal used by the university that enables students and teachers to send messages, participate in debates, and for teachers to post programs, materials etc.) so that all students could access them.

To illustrate this process of doing web searches, reporting to class and reinforcing findings with Power Point presentations, we will look at an example taken from the third lesson of unit 2 of this course, The Colonial Period. This lesson (interactive lecture) took place after the students had discussed the reasons why the English had decided to settle in North America and had been asked to do web searches to find the answers to the following questions:

1) Which were the first English settlements in North America?

2) Which were the first 13 colonies?

3) What was colonial life like? 
These questions were given to the students at the end of a lesson and they had one week until the following session. At the beginning of the day's session students were reminded to take out their name tags, that is a piece of construction paper with the student's name on it, which would stand in front of them. The reason for having their names in front of them was to improve the interpersonal relationship between themselves and the lecturer, since it has been proven that a shorter distance between participants in a communicative event determines the success of interaction (Rounds 1987; Flowerdew \& Miller, 1996; Morell 2004a, 2004b). At the same time, the questions were visualized on the screen and those students who had done the web searches informed the class secretary, who took note of their names. We began with the first question and volunteers who had done the research provided us with the names and details of each of the first settlements (e.g., Roanoke - Sir Walter Raleigh, Jamestown the Virginia Co., Plymouth - the Pilgrims). Approximately, ten out of the forty-five students intervened to give some information of interest (e.g., where they were located, how they were financed, what hardships they had to face, etc.) or to clarify a point which another student had made. In most cases the lecturer asked for others to confirm or to elaborate on a specific finding. Once the first question, "Which were the first English settlements?", was answered by the students, the lecturer moved the Power Point presentation onto the slides which also gave responses to the question and reinforced what the students had already stated. The same procedure was followed for the other two questions. Thus, by the end of the session the three questions had been discussed and taken note of by all the students in the class, and the lecturer provided them with two other questions for the following class meeting.

\section{Designing the tool for evaluation}

The on-going assessment not only consisted of students' involvement in the web searches, but also their participation in the design of the final exam and their performance on it. The exam was derived from a corpus of questions formulated by the students. On the first day of class each student was asked to sign their name under one of the twelve units of the course together with three other students. Each group of four students was responsible for making up 10 short answer questions and 5 long answer questions for the unit. The groups were to get together as soon as the unit had been covered in class and to formulate the questions. These questions were sent to the lecturer via Virtual Campus, at most, one week after the unit had been completed in class. Once the lecturer had checked that the questions were well written, and that they followed the criteria for good questions (as had been previously established in class) they were posted on the Virtual Campus so that all students could have access to them. Thus, students were provided with possible exam questions starting early in the semester. By the end of the semester, each group (A \& B) had a total of 120 short answer questions and 60 long answer questions. The responses to the questions were not provided, so that students would be obliged to review their notes and find the answers. The exam consisted of 25 short answer questions and 10 longer answer questions chosen by the lecturer from the entire corpus of questions.

\section{The effects of compiling content and designing evaluation tool}

The effects of this action research can be determined from:

1. The degree of student participation (in the web searches, in their reports to class, in the writing up of exam questions) 
2. Their exam results and

3. Their feedback, which was gathered through an end of year questionnaire.

\section{The degree of student participation}

Throughout the semester, the class secretary aided the lecturer in taking note of the students who carried out bibliographic or web searches, as well as the students who took part in class discussions. The lecturer and the virtual campus controlled the writing up of the exam questions. In addition, students were asked in the final questionnaire if and to what extent they had participated in each of the activities (searches, discussions, exam questions). The table below summarizes the degree of student participation as determined by the lecturer, two class secretaries (one for each group), virtual campus and students' questionnaire.

As is indicated below, approximately three-quarters of the students carried out the web searches and nearly the same proportion took part in the lecture discussions, which aimed to answer the questions posed the previous week. All of the students, except one, were given credit for writing up exam questions.

Table 1. The degree of students' participation in web searches, class discussions and exam questions

\begin{tabular}{|l|c|c|c|c|}
\hline & $\begin{array}{c}\text { Students enrolled } \\
\text { (Group A + B) }\end{array}$ & $\begin{array}{c}\text { Students who } \\
\text { carried out web } \\
\text { searches (at least } \\
1 \text { ) }\end{array}$ & $\begin{array}{c}\text { Students who } \\
\text { participated in } \\
\text { discussions (at } \\
\text { least 1) }\end{array}$ & $\begin{array}{c}\text { Students who } \\
\text { wrote up exam } \\
\text { questions }\end{array}$ \\
\hline No. of Students & 86 & 64 & 62 & 85 \\
\hline$\%$ of Students & $100 \%$ & $74.4 \%$ & $72.1 \%$ & $98.8 \%$ \\
\hline
\end{tabular}

\section{Exam results}

The average grade obtained by the students was an 8.4 , which was 1.7 points higher than the average grade obtained by the students in the previous year. In the former year students had not taken part in web searches and had not been involved in contributing possible questions for the exam. Therefore, we may deduce that the different methodology used contributed to the increase in grades.

Table 2. Exam results

\begin{tabular}{|c|c|c|c|c|}
\hline Students & Passing & Average & Max grade & Min grade \\
\hline 86 & 84 & 8.4 & 10.0 & 4.7 \\
\hline
\end{tabular}

\section{Students' feedback from questionnaires}

On the day of the final exam the students were asked to fill in the questionnaire that appears in the Appendix. A total of 76 students of the possible 86 responded to the questions, 
and of these $48.7 \%$ stated that they had attended class more than $80 \%$ of the time and $23.7 \%$ claimed that they attended between 60 and $80 \%$ of the classes. Most of them carried out some of the web searches and all of those who had at least carried out a few found them to be useful. Some of the reasons they gave for their positive evaluation were that:

- They learned how to carry out effective web searches (and for some, it was the first time they were using the web for research purposes).

- They learned interesting things on their own.

- It made the classes different because the teacher was not the only person informing.

- They spoke more than usual.

All of the students, except one, had been recorded as having written exam questions, but according to their responses to the questionnaire not all of them believed they had taken an active role. $96.1 \%$ thought it had been useful to write the exams and to have a corpus from which the exam was designed. The reasons they gave could be summarized as follows: It was useful because

- They had the opportunity to work in groups.

- They realized that a teacher's job of writing up exam questions is not easy.

- It made them think more about the material and to study beforehand (not just the day before the exam).

- The majority claimed that that they had studied in a more effective way than usual.

- They believed that they had learned more than in a traditional set up.

In their suggestions for the future, a few students thought it would have been more effective if they only had to answer one question per week (via web searches), so that different groups of students would be involved with each question. In such a manner, students could be more thorough in their particular question and they would listen more to the students who had found the answers to the other questions. The lecturer took up this suggestion in the current year and students seem to be satisfied with this arrangement.

Some students also thought that the lecturer should be stricter with demanding that each group hand in their possible exam questions within the week after the unit had been completed, since some groups were delayed. This year students have been notified that they will obtain extra credit for handing the questions on time, and thus far they have been punctual.

\section{Conclusion}

The action research presented in this paper can be considered a preliminary response to a well spread problem found among many university students who are taking content subjects in English and who are not necessarily intrinsically motivated to learn the language and the content. This small-scale study provides evidence that it is possible to involve students in the material (content and language) to be studied and to be more fully integrated within the evaluation procedure. Nevertheless, on another level this action research can be brought beyond the two classrooms of this study, that is the problem identified is not exclusive to 
these particular students and lecturer and the plan carried out can be adopted to many other classrooms. As stated by Crookes (1993: 134), action research can be a cyclical program of reform, whose results are reflected on and further refined and developed in collaborative investigative communities.

As has been verified by the students' responses to the questionnaire, the incorporation of web searches and students' involvement within the evaluation process benefits the students. To begin with, students acquire practice in carrying out successful web searches and become aware of the wealth of information found in the Internet, especially in English. Consequently, they have read, summarized and reported their findings in English, much more than if they had simply been asked to read and report on an assigned chapter from a textbook. In fact, the students who took part in this action research participated much more than those from previous years, who had only been assigned readings from textbooks and articles. In addition, these students, who mostly want to be teachers of the English language, realize that in today's world it is not so much what you know, but how you can find the information needed.

This manner of carrying out content lectures for EFL students who not only need to understand the content, but also to improve their communicative competence has proven to be beneficial not only for the learners, but also for the lecturer. Being that the lecturer takes on the role of facilitator, instead of informer, the students take on a more active role and thus provide the lecturer with valuable information. The lecturer obtained information about their comprehension, competence level, and even facts and perspectives that the lecturer may not have considered previously. Thus, the lecturer is able to effectively guide the students with both the content and the language as well as to increase his/her own grasp of the material and of the manner in which it needs to be taught.

However, there are some drawbacks on this methodology, such as the time component and the increased amount of work when there are large groups of students. Carrying out this type of interactive lecture requires instructors to do previous web searches, selection of relevant material, construction of Power Point presentations, keeping track of students' participation, monitoring exam question formulation, posting well written exam questions, selection of relevant questions, grading and being open to constructive criticism. In addition, in many university classes the numbers of students may discourage lecturers to attempt any innovative methodology since they believe that it is impossible to control the many factors involved together with the many students (e.g., 80 to 100 students). In such cases, it is highly recommended that lecturers rely more on group work and on the more highly motivated students who volunteer to help. These students can be asked to be group leaders that report on the groups' work. Although at first sight this may appear to be overwhelming, in the long run it will prove to be beneficial. Obviously, it is much easier to assign reading assignments and to give traditional lectures, where you simply have to deliver structured comprehensible information and at the end of the semester give the students a final exam. In such cases, it would be just as effective to post the lecture online or to give the students a photocopied version of the lecture.

On the contrary, developing courses that are relevant to the needs and interests of the students will motivate them to learn. According to Nunan (1996: 211), involving learners in the decision-making process about what to learn and how to learn and encouraging them to take responsibility for their own learning can be a major way of enhancing motivation. 


\section{BibLIOGRAPHY}

Bernabeu Pastor, G. \& Sauleda Parés, N. (eds.)(2004). Espacios de investigación en la profesionalización docente universitaria. Alcoy: Editorial Marfil.

Campbell, N. \& Kean, A. (1997). American Cultural Studies: An Introduction to American Culture. London: Routledge.

Crookes, G. (1993). "Action research for second language teachers: Going beyond teacher research. Applied Linguistics, 14 (2), 130-144.

Dunkel, P. (1988). "The content of L1 and L2 students' lecture notes and its relation to tests performance". TESOL Quarterly. 22 (2), 259-282.

Falk, R. (1993). Spotlight on the U.S.A. New York: Oxford University Press.

Flowerdew, J. (ed.)(1994). Academic Listening: Research Perspectives. Cambridge: Cambridge University Press.

Flowerdew J. \& Miller, L. (1996). "Lectures in a second language: Notes towards a cultural grammar". English for Specific Purposes. 15(2), 121-140.

Frederick, P.J. (1986). "The lively lecture - 8 variations". College Teaching. 34 (2), 43-50.

Gardner, R.C. \& Lambert, W.E. (1972). Attitudes and Motivation in Second Language Learning. Massachusetts: Newbury House Publishers.

Gebrard, J. \& Oprandy R. (1999). Language Teaching Awareness: A Guide to Exploring Beliefs and Practices. Cambridge: Cambridge University Press.

González Torres, M ${ }^{\mathrm{a} C}$. (1997). La motivación académica. Pamplona: Ediciones: Universidad de Navarra.

Martínez, M.A. (coord.)(2004). Investigar en docencia universitaria: Redes de colaboración para el aprendizaje. Alcoy: Marfil.

Mauk, D. \& Oakland, J. (2002). American Civilization: An Introduction. $3^{\text {rd }}$ Edition. London: Routledge.

Morell, T. (2000). EFL Content Lectures: A Discourse Analysis of an Interactive and a NonInteractive Style. Departamento de Filología Inglesa, Universidad de Alicante. Working Papers 7.

Morell, T. \& Alesón, MªA. (2004). "La participación de los discentes en la evaluación del aprendizaje" en M.A. Martínez (coord.) Investigar en docencia universitaria. Alcoy: Marfil.

Morell, T. (2004a). La interacción en la clase magistral. Alicante: Servicio de Publicaciones de la Universidad de Alicante.

Morell, T. (2004b). "Interactive lecture discourse for university EFL students". English for Specific Purposes. 23(3) 325-338.

Northcott, J. (2001). "Towards an ethnography of the MBA classroom: a consideration of the role of interactive lecturing styles within the context of one MBA programme". English for Specific Purposes. 20, 15-37.

Nunan, D. (1996). The Self-Directed Teacher: Managing the Learning Process. Cambridge: Cambridge University Press.

Richards, J.C. \& Lockhart, C. (1996). Reflective Teaching in Second Language Classrooms. Cambridge: Cambridge University Press.

Rounds, P. (1987). "Characterizing successful classroom discourse for NNS teaching assistant training". TESOL Quarterly. 21(4), 643-669.

Schleppegrell, M.J., Achugar, M. \& Oteíza, T. (2004). "The grammar of history: Enhancing contentbased instruction through a functional focus on language". TESOL Quarterly 38(1), 67-93.

Van Lier, L. (1988). The Classroom and the Language Learner. London: Longman. 
Wallace, M.J. (1991). Training Foreign Language Teachers. Cambridge: Cambridge University Press.

Wesche, M.B. \& Ready, D. (1985). "Foreigner talk in the university classroom" in Gass \& Madden (eds.). Input in Second Language Acquisition. Cambridge, Mass.: Newbury.

\section{APPENDIX}

\section{Questionnaire for students of U.S. History \& Culture}

1. I attended of the classes of U.S. History \& Culture
a. all
b. more than $80 \%$
c. between 60 and $80 \%$
d. less than $60 \%$
e. none

2. I carried out of the web searches.
a. all
b. many
c. some
d. a few
e. none

3. I believe doing the web searches was
a. useless
b. useful

Why?

3. Underline the appropriate response. I took/did not take an active role in writing up questions for the exam.

4. I believe the idea of students writing up questions for the exam was
a. useless
b. useful

Why?

5. Would you have preferred to have a more traditional type of lecture class for U.S. History and Culture? Why or Why not?

Please add any comments or suggestions to improve students' participation in future years

Thank you for your collaboration. 